Journal of Organometallic Chemistry, 308 (1986) 289-296

Elsevier Sequoia S.A., Lausanne - Printed in The Netherlands

\title{
THE EXCHANGE REACTION OF TETRAMETHYLDIPNICTOGENS WITH DIMETHYLDICHALCOGENIDES
}

\author{
ARTHUR J. ASHE III ${ }^{\star}$ and EDWARD G. LUDWIG, Jr. \\ Department of Chemistry, The University of Michigan, Ann Arbor, Michigan 48109 (U.S.A.) \\ (Received October 10th, 1985; in revised form January 17th, 1986)
}

\section{Summary}

Tetramethyldipnictogens $\mathrm{Me}_{4} \mathrm{E}_{2}(\mathrm{E}=\mathrm{P}, \mathrm{As}, \mathrm{Sb}, \mathrm{Bi})$ undergo exchange reactions with dimethyldichalcogenides $\mathrm{Me}_{2} \mathrm{~A}_{2}(\mathrm{~A}=\mathrm{S}, \mathrm{Se}, \mathrm{Te})$ to produce the corresponding (dimethylpnicto)methylchalcogenides $\mathrm{Me}_{2} \mathrm{EAMe}$. These compounds have been characterized by NMR, Raman and mass spectroscopy.

\section{Introduction}

In the course of a study of element-element bonding of tetraorganodipnictogens $R_{4} E_{2}$ (E = P, As, Sb, Bi) [1-3] we became interested in obtaining related compounds containing hetero element-element bonds. In a previous paper we reported that interpnictogen compounds $\mathrm{Me}_{2} \mathrm{EE}^{\prime} \mathrm{Me}_{2}$ could be prepared by the exchange reaction of the corresponding tetramethyldipnictogens (eq. 1) [4].

$\mathrm{Me}_{4} \mathrm{E}_{2}+\mathrm{Me}_{4} \mathrm{E}_{2}^{\prime} \rightleftharpoons 2 \mathrm{Me}_{2} \mathrm{EE}^{\prime} \mathrm{Me}_{2}$

(1) (1')

$$
\begin{aligned}
&\left(E^{\prime} \neq \mathrm{E}\right. \text { a, } \mathrm{E}=\mathbf{P} \\
& \text { b, } \mathrm{E}=\mathrm{As} \\
& \text { c, } \mathrm{E}=\mathrm{Sb} \\
&\text { d, } \mathrm{E}=\mathrm{Bi})
\end{aligned}
$$

$\mathrm{Me}_{4} \mathrm{E}_{2}+\mathrm{Me}_{2} \mathrm{~A}_{2} \rightleftharpoons 2 \mathrm{Me}_{2} \mathrm{EAMe}$

(1) $\quad(3, A=S ; \quad(6, A=S$;

$$
\begin{array}{ll}
4, \mathrm{~A}=\mathrm{Se} ; & 7, \mathrm{~A}=\mathrm{Se} ; \\
\mathrm{5}, \mathrm{A}=\mathrm{Te}) & \mathbf{8}, \mathrm{A}=\mathrm{Te})
\end{array}
$$

(Diorganopnicto)organochalcogenides $R_{2} E A R$ may be prepared by a similar reaction of $R_{4} E_{2}$ and $R_{2} A_{2}(A=S, S e, T e)$. Grobe and coworkers have reported on a systematic investigation of the exchange reaction of diphosphines and diarsines with dichalcogenides [5-7]. More recently several (diorganoarsino)organotellurides $\mathbf{R}_{2} \mathrm{AsTeR}^{\prime}$ [8], (diorganostibino)organotellurides $\mathrm{R}_{2} \mathrm{SbTeR}^{\prime}[9,10]$ and a (diorgano- 
bismuthino)organotelluride $\mathrm{R}_{2} \mathrm{BiTe}^{\prime}$ [11] have been prepared via the exchange reaction of a ditelluride with the corresponding tetraorganodipnictogens.

On the other hand, a number of (diorganopnicto)organosulfides have been obtained by displacement reactions [12-15]. Since samples of all of the tetramethyldipnictogens were available to us, we have explored their exchange with all of the dimethyldichalcogenides 3-5. This has allowed us to explore the generality of the reaction and to obtain spectroscopic characterization of the (dimethylpnicto)methylchalcogenides 6-8 which had not previously been reported.

\section{Results and discussion}

\section{Exchanges with dimethylditelluride}

We find that the tetramethyldipnictogens $\left(\mathrm{Me}_{4} \mathrm{E}_{2}, \mathrm{E}=\mathrm{P}, \mathrm{As}, \mathrm{Sb}, \mathrm{Bi}\right)$ undergo rapid exchange with dimethylditelluride at $25^{\circ} \mathrm{C}$ in solution or as neat liquids. The ${ }^{1} \mathrm{H}$ NMR spectra of mixtures of either tetramethyldiphosphine or tetramethyldiarsine with dimethylditelluride in benzene- $d_{6}$ show signals for both the parent compounds and mixed compounds $\mathbf{8 a}$ and $\mathbf{8 b}$, respectively. The relative concentration of each species was determined by integration of the proton signals. The equilibrium constants were calculated using the following expression:

$K=\left[\mathrm{Me}_{2} \mathrm{EAMe}\right]^{2} /\left[\mathrm{Me}_{4} \mathrm{E}_{2}\right]\left[\mathrm{Me}_{2} \mathrm{~A}_{2}\right]$

The equilibrium constants at $25^{\circ} \mathrm{C}$ are 63 and $3 \times 10^{-2}$ for formation of $8 \mathrm{~b}$ and $8 \mathrm{a}$, respectively.

On the other hand, mixtures of either tetramethyldistibine or tetramethyldibismuthine with dimethylditelluride were completely converted to (dimethylstibino)methyltelluride (8c) or (dimethylbismuthino)methyltelluride (8d), respectively. Based upon our estimated levels of detection of starting materials, the equilibrium constants must exceed $10^{3}$.

\section{NMR spectra}

The proton NMR data for $\mathbf{8 a - 8 d}$ are summarized in Table 1. Data for $\mathbf{8 b}$ are consistent with those reported by Grobe [5]. Relative assignments may be made easily since the signals for the methyl groups attached to the pnictogen atom are twice as intense as those for the methyl groups attached to tellurium. This assignment is consistent with the ${ }^{125} \mathrm{TeH}$ coupling constants. For $8 \mathbf{a}, \mathbf{8 b}$ and $8 \mathbf{c}$, the ${ }^{2} J(\mathrm{TeH})$ is approximately $21 \mathrm{~Hz}$, only slightly smaller than the $23.6 \mathrm{~Hz}$ shown for $\mathrm{Te}_{2} \mathrm{Me}_{2}$ [16]. On the other hand, the smaller ${ }^{3} J(\mathrm{TeH})$ values for $\mathrm{Me}_{2} \mathrm{ETeMe}$ increase in the series $\mathbf{E}=\mathbf{S b}<\mathrm{As}<\mathrm{P}$. The proton signals for $8 \mathrm{~d}$ were so broad that the $J(\mathrm{TeH})$ values could not be determined.

The proton-noise decoupled ${ }^{125}$ Te NMR spectra of $8 \mathbf{a}-8 \mathbf{d}$ have been measured in benzene- $d_{6}$. Excess dimethylditelluride served as an internal reference at $\delta 63 \mathrm{ppm}$. The ${ }^{125}$ Te chemical shift data of $\mathbf{8 a - 8 d}$ and some related compounds are collected in Table 2.

The ${ }^{125} \mathrm{Te}$ NMR resonances occur over a large range. The chemical shift value of $8 \mathrm{a}$ at $90 \mathrm{ppm}$ is more than $350 \mathrm{ppm}$ downfield from $\delta-277$ ppm shown by $8 \mathrm{~d}$. There is a progressive Te-shielding in the series $\mathrm{Me}_{2} \mathrm{ETeMe}$ as $\mathrm{E}$ changes from phosphorus to bismuth. A similar trend is shown by $p$-tolyltellurium derivatives TolTeER $_{2}(E=P, S b, B i)[11,17]$, although differences in pnictogen substitution 
TABLE 1

PROTON NMR DATA FOR THE(DIMETHYLPNICTO)METHYLCHALCOGENIDES, $\mathrm{Me}_{2} \mathrm{EAMe}^{a}$

\begin{tabular}{|c|c|c|c|c|c|}
\hline Compound & $\begin{array}{l}\delta\left(\mathrm{Me}_{2} \mathrm{EAMe}\right) \\
(\mathrm{ppm})\end{array}$ & ${ }^{3} J(\mathrm{AH})(\mathrm{Hz})^{b}$ & $\begin{array}{l}\delta\left(\mathrm{Me}_{2} \mathrm{EA} M \mathrm{e}\right) \\
(\mathrm{ppm})\end{array}$ & ${ }^{2} J(\mathrm{AH})(\mathrm{Hz})^{b}$ & $J(\mathrm{PH})(\mathrm{Hz})$ \\
\hline$\overline{\mathrm{Me}_{2} \mathrm{PSMe}(6 \mathrm{a})}$ & $1.08^{c}$ & - & $1.88^{c}$ & - & ${ }^{2} J(\mathrm{PH}) 6.4 ;{ }^{3} J(\mathrm{PH}) 9.8^{c}$ \\
\hline $\mathrm{Me}_{2} \operatorname{AsSMe}(6 \mathrm{~b})$ & $1.05^{d}$ & - & $1.97^{d}$ & - & - \\
\hline $\mathrm{Me}_{2} \mathrm{SbSMe}(6 \mathrm{c})$ & 0.81 & - & 2.03 & - & - \\
\hline $\mathrm{Me}_{2} \operatorname{PSeMe}(7 \mathrm{a})$ & $1.21^{e}$ & 8.2 & $1.78^{\circ}$ & 10.5 & ${ }^{2} J(\mathrm{PH})={ }^{3} J(\mathrm{PH})=7.0^{e}$ \\
\hline $\mathrm{Me}_{2} \mathrm{AsSeMe}(7 \mathrm{~b})$ & $1.14^{f}$ & 6.5 & $1.85^{f}$ & 8.5 & - \\
\hline $\mathrm{Me}_{2} \mathrm{SbSeMe}(7 \mathrm{c})$ & 0.90 & 3.7 & 1.85 & 9.9 & - \\
\hline $\mathrm{Me}_{2} \mathrm{BiSeMe}(\mathbf{7 d})$ & $1.28(\mathrm{br} \mathrm{s})$ & - & 2.29 (br s) & - & - \\
\hline $\mathrm{Me}_{2}$ PTeMe (8a) & 1.41 & 16.6 & 1.67 & 21.0 & ${ }^{2} J(\mathrm{PH}) 7.3 ;{ }^{3} J(\mathrm{PH}) 4.6$ \\
\hline $\mathrm{Me}_{2} \mathrm{AsTeMe}(\mathbf{8 b})$ & $1.30^{\mathrm{g}}$ & 10.3 & $1.73^{\mathrm{g}}$ & 20.6 & - \\
\hline $\mathrm{Me}_{2} \mathrm{SbTeMe}(8 \mathrm{c})$ & 1.07 & 7.6 & 1.69 & 20.5 & - \\
\hline $\mathrm{Me}_{2} \mathrm{BiTeMe}(\mathbf{8 d})$ & $1.45(\mathrm{br} \mathrm{s})^{h}$ & - & $2.07(\mathrm{br} \mathrm{s})^{n}$ & - & - \\
\hline
\end{tabular}

a The solvent is benzene- $d_{6}$ unless noted otherwise. Chemical shifts are relative to TMS. ${ }^{b} \mathbf{A}$ refers to ${ }^{125}$ Te or ${ }^{77} \mathrm{Se} .{ }^{c}$ Literature values $\delta 1.25,2.04 ;{ }^{2} \mathrm{~J}(\mathrm{PH}) 6.5,{ }^{3} J(\mathrm{PH})$ 9.8. Ref. 15. ${ }^{d}$ Literature values $\delta 1.25$, 2.10. Ref. 14. ${ }^{e}$ Literature values $\delta 1.25,1.82 ;{ }^{2} J(\mathrm{PH}) 7.2,{ }^{3} J(\mathrm{PH}) 7.4$. Ref. $5 .{ }^{\prime}$ Literature values $\delta 1.23$, 1.90. Ref. 5. ${ }^{g}$ Literature values $\delta 1.47,1.82$. Ref. $5{ }^{h}$ The solvent is toluene- $d_{8}$.

make the comparison tenuous. Very large substituent effects on the ${ }^{125} \mathrm{Te}$ chemical shift values have been found for dialkylditellurides [18,19].

(Dimethylphosphino)methyltelluride was also detected by ${ }^{31} \mathbf{P}$ NMR spectroscopy. The compound shows a signal at $\delta-33.4 \mathrm{ppm}$ with easily observable satellites arising from ${ }^{125} \mathrm{Te}$ coupling $\left({ }^{1} \mathrm{~J}(\mathrm{PTe}) 397 \mathrm{~Hz}\right.$ ). The value of the TeP coupling constant is similar to that shown by other singly bonded TeP compounds [17].

\section{Exchanges with dimethyldiselenide and dimethyldisulfide}

In an identical manner we find that the tetramethyldipnictogens undergo rapid reaction with dimethyldiselenide to give the corresponding (dimethylpnicto)methyl-

\section{TABLE 2}

TELLURIUM-125 NMR CHEMICAL SHIFT VALUES FOR (DIORGANOPNICTO)ORGANOTELLURIDES $R_{2}$ ETeR' (E = P, As, Sb, Bi) AND SELECTED DIORGANODITELLURIDES

\begin{tabular}{lcc}
\hline Compound & $\delta(\mathbf{p p m})$ & ${ }^{1} J(\mathrm{PTe})(\mathrm{Hz})$ \\
\hline MeTeTeMe (5) $_{\text {MeTePMe }}$ (8a) & 63 & - \\
MeTeAsMe $_{2}$ (8b) & 90 & 397 \\
MeTeSbMe $_{2}$ (8c) & 34 & - \\
MeTeBiMe $_{2}$ (8d) & -271 & - \\
TolTeTeTol $_{\text {TolTeP(t-Bu) }}$ & -277 & - \\
TolTeP(i-Pr) & $432.2^{a}$ & - \\
TolTeSbMe & $241.4^{b}$ & $556^{c}$ \\
TolTeBi(n-Pr) & $197.4^{b}$ & $553^{c}$ \\
\hline
\end{tabular}

${ }^{a}$ Ref. 19. Solvent is $\mathrm{CHCl}_{3}{ }^{b}$ Ref. 10. Adjusted to standard $\mathrm{Me}_{2} \mathrm{Te} \delta=0 .{ }^{c}$ Ref. 17. 
selenides 7. The ${ }^{1} \mathrm{H}$ NMR spectra of the reaction mixtures of each of the tetramethyldipnictogens with dimethyldiselenide in benzene- $d_{6}$ indicate complete conversion to 7. Based upon our estimated limits of detection of starting material the equilibrium constants must be $>10^{3}$ for formation of $7 \mathbf{a}-7 \mathrm{~d}$.

The ${ }^{1} \mathbf{H}$ NMR data are collected in Table 1 . The chemical shift values of $7 \mathbf{a}$ and 7b are essentially identical to those previously reported by Grobe [5]. The ${ }^{77} \mathrm{Se}-{ }^{1} \mathrm{H}$ coupling constants of $7 \mathbf{a}, 7 \mathbf{b}$ and $7 \mathrm{c}$ follow a trend similar to that observed for ${ }^{125} \mathrm{Te}-\mathrm{H}$ coupling constants of 8 . Thus, the ${ }^{2} J\left({ }^{77} \mathrm{SeH}\right)_{2}$ are slightly smaller than that of dimethyldiselenide $\left({ }^{2} J\left({ }^{77} \mathrm{SeH}\right) 11.9 \mathrm{~Hz}\right)[20]$ and they show only small variation in the series. On the other hand, the smaller ${ }^{3} J\left({ }^{77} \mathrm{SeH}\right)$ values increase in the series $\mathrm{Me}_{2} \mathrm{ESeMe}, \mathrm{E}=\mathrm{Sb}<\mathrm{As}<\mathrm{P}$.

We also find that tetramethyldiphosphine, tetramethyldiarsine and tetramethyldistibine undergo exchange reactions with dimethyldisulfide to produce the corresponding (dimethylpnicto)methylsulfides 6. The equilibrium constants at $25^{\circ} \mathrm{C}$ are 28,77 and 200 for the formation of $6 \mathrm{a}, \mathbf{6 b}$ and $6 \mathrm{c}$, respectively. We were not able to detect exchange with tetramethyldibismuthine. However, since (diorganobismuthino)organosulfides have been prepared by displacement reactions, the equilibria are likely to be highly favorable [11]. Compounds $6 a$ [15] and $6 b$ [14] have previously been reported. Proton NMR spectral data are collected in Table 1.

\section{Raman spectra}

We have found Raman spectroscopy to be an extremely useful method for characterizing the (dimethylpnicto)methylchalcogenides 6-8. Metal-metal (or heavy element-heavy element) stretching vibrations normally give rise to intense and easily identifiable Raman peaks. For each of the compounds $\mathrm{Me}_{2} \mathrm{EAMe}$ we observe strong bands assigned to the $E-A$ stretch at frequencies intermediate between the $E-E$ bands of the corresponding tetramethyldipnictogen and the A-A bands of the corresponding dimethyldichalcogenide. However, in the case of bismuth compounds 7d and $8 d$ we were unable to observe the BiA bands. Apparently the deeply colored bismuth compounds were destroyed by the laser exciting radiation. The Raman data are collected in Table 3.

Spectral assignments listed in Table 3 are consistent with the relatively few data available for compounds containing E-A bonds. Previous assignments for the PS, AsS and AsSe stretching frequencies of $6 \mathrm{a}$ [15], $6 \mathrm{~b}$ [14] and 7b [14] agree within 10 $\mathrm{cm}^{-1}$ with the present data. Raman spectra for a series of bis(diorganostiba)telluranes [9] -selenanes [9] and -sulfides [21] $\left(\mathrm{R}_{2} \mathrm{Sb}\right)_{2} \mathrm{E}$ have been reported by Breunig and coworkers. Interestingly the assignments for bands from $\mathrm{SbS}\left(335 \mathrm{~cm}^{-1}\right), \mathrm{SbSe}$ $\left(225 \mathrm{~cm}^{-1}\right)$ and $\operatorname{SbTe}\left(180 \mathrm{~cm}^{-1}\right)$ vibrations are identical to those found for $6 \mathrm{c}, 7 \mathrm{c}$ and $8 c$, respectively. A series of triorganopnicto-chalcogenides $R_{3} E A$ including compounds $\mathrm{R}_{3} \mathrm{SbS}, \mathrm{R}_{3} \mathrm{SbSe}$ and $\mathrm{R}_{3} \mathrm{PTe}$ have been examined by Zingaro [22]. In each case the band assigned to $E=A$ stretch occurs at higher frequency than the corresponding EA band for the $\mathrm{Me}_{2} \mathrm{EAMe}$. This shift is consistent with the expected multiple bond character of EA bonds of compounds $R_{3} E A$.

The fundamental EA stretching frequencies for all of compounds $\mathrm{Me}_{2} \mathrm{EAMe}$ can be accurately estimated using Gordy's empirical equation (eq. 4) [23]. This equation expresses the force constant $(k)$ for an isolated EA vibration in terms of the Pauling electronegativities $\left(\chi_{\mathrm{A}}, \chi_{\mathrm{E}}\right)$ [24] and the EA bond distance $(d)$, estimated from the sum of the Pauling covalent radii [25]. Substituting $k$ and the reduced mass $\mu$ of 
TABLE 3

SUMMARY OF THE ELEMENT-ELEMENT STRETCHING VIBRATIONS OF THE (DIMETHYLPNICTO)METHYLCHALCOGENIDES (Me, EAMe), THE DIMETHYLDICHALOGENIDES $\left(\mathrm{Me}_{2} \mathrm{~A}_{2}\right)$ AND THE TETRAMETHYLDIPNICTOGENS $\left(\mathrm{Me}_{4} \mathrm{E}_{2}\right)$ FROM THE RAMAN SPECTRA. A COMPARISON WITH FREQUENCIES CALCULATED USING GORDY'S RULE

\begin{tabular}{|c|c|c|c|c|}
\hline Compound & $\begin{array}{l}\text { Observed } \\
\nu\left(\mathrm{cm}^{-1}\right)\end{array}$ & $\begin{array}{l}\text { Calcd. } \\
\nu\left(\mathrm{cm}^{-1}\right)\end{array}$ & $\begin{array}{l}\text { Difference } \\
\left(\mathrm{cm}^{-1}\right)\end{array}$ & Assignment \\
\hline $\mathrm{Me}_{4} \mathrm{P}_{2}$ (1a) & $455,425^{a}$ & 452 & -3 & P-P \\
\hline $\mathrm{Me}_{4} \mathrm{As}_{2}(\mathbf{1 b})$ & $272,254^{b}$ & 266 & -6 & As-As \\
\hline $\mathrm{Me}_{4} \mathrm{Sb}_{2}(1 \mathrm{c})$ & $175,143^{c}$ & 185 & +10 & $\mathbf{S b}-\mathbf{S b}$ \\
\hline $\mathrm{Me}_{2} \mathrm{~S}_{2}(3)$ & $505^{d}$ & 517 & +12 & $\mathbf{S}-\mathbf{S}$ \\
\hline $\mathrm{Me}_{2} \mathrm{Se}_{2}$ (4) & $286^{e}$ & 273 & -13 & $\mathrm{Se}-\mathrm{Se}$ \\
\hline $\mathrm{Me}_{2} \mathrm{Te}_{2}(5)$ & $188^{f}$ & 195 & +7 & $\mathrm{Te}-\mathrm{Te}$ \\
\hline $\mathrm{Me}_{2} \operatorname{PSMe}(6 \mathrm{a})$ & $470^{8}$ & 483 & +13 & $\mathbf{P}-\mathbf{S}$ \\
\hline $\mathrm{Me}_{2} \mathrm{AsSMe}(6 \mathrm{~b})$ & $386,372^{h}$ & 382 & -4 & As-S \\
\hline $\mathrm{Me}_{2} \mathrm{SbSMe}(6 c)$ & 335 & 338 & +3 & $\mathbf{S b}-\mathrm{S}$ \\
\hline $\mathrm{Me}_{2} \mathrm{PSeMe}(\mathbf{7 a})$ & 383,368 & 382 & -1 & P-Se \\
\hline $\mathrm{Me}_{2} \mathrm{AsSeMe}(\mathbf{7 b})$ & $277,261^{i}$ & 289 & +12 & As-Se \\
\hline $\mathrm{Me}_{2} \mathrm{SbSeMe}(7 \mathrm{c})$ & 233,225 & 236 & +3 & $\mathrm{Sb}-\mathrm{Se}$ \\
\hline $\mathrm{Me}_{2} \mathrm{PTeMe}$ (8a) & 334 & 328 & -6 & P-Te \\
\hline $\mathrm{Me}_{2} \mathrm{AsTeMe}(\mathbf{8 b})$ & 233 & 239 & +6 & As-Te \\
\hline $\mathrm{Me}_{2} \mathrm{SbTeMe}(8 \mathrm{c})$ & 179 & 190 & +11 & $\mathrm{Sb}-\mathrm{Te}$ \\
\hline
\end{tabular}

${ }^{a}$ Ref. 25. ${ }^{b}$ Ref. 26. c Ref. 27. " "Sadtler Standard Raman Spectra," Sadtler Research Laboratories, Philadelphia, Pennsylvania (1976) 4084R. ' W.H. Green and A.B. Harvey, J. Chem. Phys., 49 (1968) 3586. ${ }^{f}$ C.W. Sink and A.B. Harvey, J. Mol. Struct., 4 (1969) $203 .{ }^{g}$ Literature value $478 \mathrm{~cm}^{-1}$. Ref. 15.

${ }^{h}$ IR value $382 \mathrm{~cm}^{-1}$. Ref. 14. ${ }^{i}$ IR value $280 \mathrm{~cm}^{-1}$ (?). Ref. 14.

atoms $A$ and $E$ into the equation of the harmonic oscillator (eq. 5) gives the calculated frequencies tabulated in Table 3 . The estimated values are very close to the experimental values. The average difference is only $\pm 7 \mathrm{~cm}^{-1}$ while the largest deviation is only $13 \mathrm{~cm}^{-1}$. This agreement provides a considerable level of confidence in our assignments.

$k=1.67\left(\chi_{\mathrm{A}} \chi_{\mathrm{E}} / d^{2}\right)^{3 / 4}+0.30$

$\nu\left(\mathrm{cm}^{-1}\right)=1307(k / \mu)^{1 / 2}$

Compounds 7a, 7b, 7c and $6 \mathrm{~b}$ apppear to each show two EA bands. The tetramethyldipnictogens 1a [25], 1b [26], and 1c [27] also each show two bands for the E-E stretching frequencies. These bands have been assigned to trans and gauche conformers. It may be that compounds 7 and $6 \mathrm{~b}$ populate similar conformers.

\section{Mass spectra}

Finally, the (dimethylpnicto)methylchalcogenides 6a-c, 7a-c and $8 \mathrm{~b}-\mathrm{c}$ have been characterized by mass spectroscopy. Owing to their lability the mass spectra of 7d and $8 \mathrm{~d}$ could not be recorded. The major fragmentation patterns are summarized in Table 4. Each compound shows easily identifiable molecular ions $\mathrm{Me}_{2} \mathrm{EAMe}^{+}$and characteristic daughter ions of $\mathrm{Me}_{2} \mathrm{EA}^{+}, \mathrm{MeEA}^{+}, \mathrm{EA}^{+}, \mathrm{Me}_{2} \mathrm{E}^{+}, \mathrm{E}^{+}, \mathrm{MeA}^{+}$and $\mathrm{A}^{+}$. 


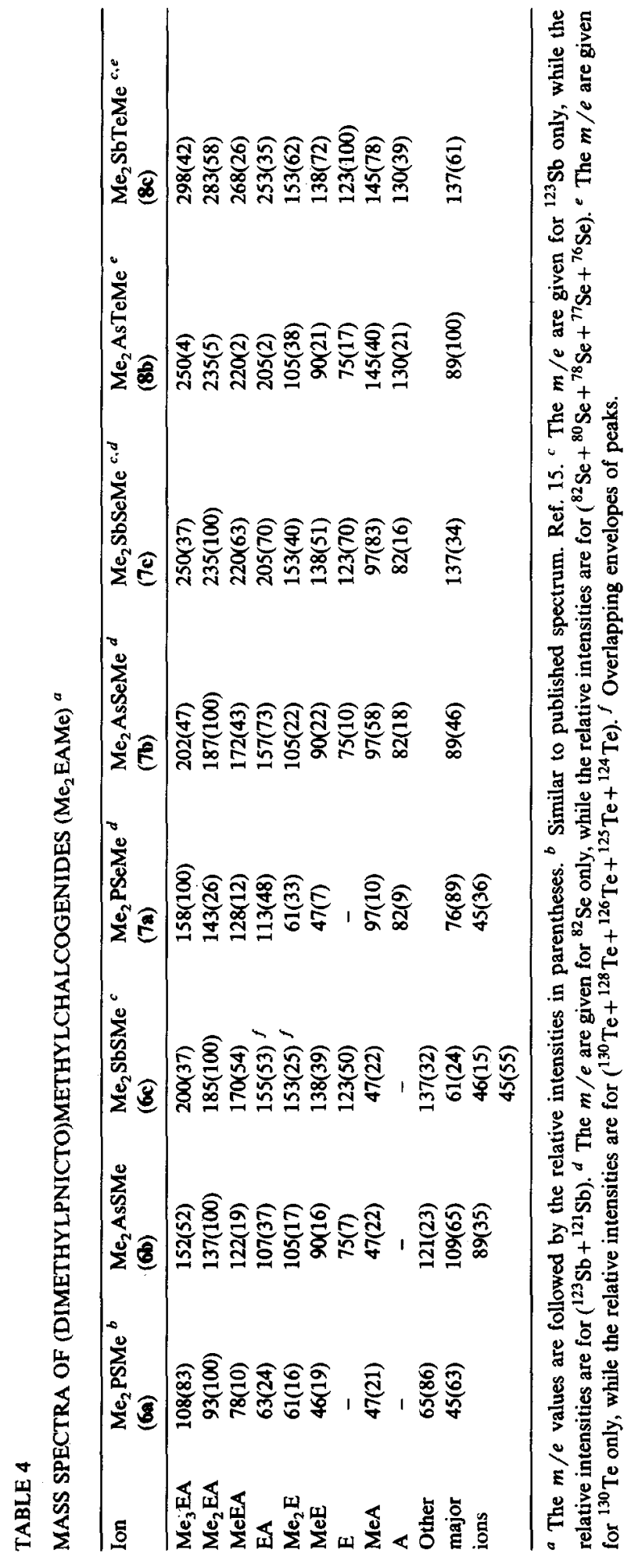




\section{Experimental}

\section{General remarks}

The proton, phosphorus and tellurium-125 NMR spectra were recorded using a Bruker WM-360 NMR spectrometer. Tetramethylsilane was used as an internal reference for the proton spectra, while $85 \% \mathrm{H}_{3} \mathrm{PO}_{4}$ was used as an external reference for the phosphorus spectrum. For the tellurium-125 NMR spectra, dimethylditelluride was used as an internal reference at $\delta 63 \mathrm{ppm}$ relative to an external sample of dimethyltelluride at $\delta 0 \mathrm{ppm}$. The tellurium chemical shifts are estimated to be \pm 1 ppm.

Mass spectral determinations were made by using a Finnigan 4023 GC/MS with an electron ionization energy of $70 \mathrm{eV}$. The various reaction mixtures were analyzed through separation by the GC/MS system. This was done by using a $6 \mathrm{ft} \times 1 / 4$ in glass column packed with 5\% SE-30. An initial column temperature of $60^{\circ} \mathrm{C}$ was increased at a rate of $10^{\circ} \mathrm{C} / \mathrm{min}$ to $200^{\circ} \mathrm{C}$ under a helium flow of $20 \mathrm{ml} / \mathrm{min}$. The injector temperature was maintained at $150^{\circ} \mathrm{C}$. Raman spectra were obtained on a Spex 1401 double spectrometer using the 6328-A excitation line of a Spectra Physics Model 125 helium neon laser.

All operations were performed under argon or nitrogen. Tetramethyldiphosphine and tetramethyldiarsine were obtained from Strem Chemical Co., dimethyldisulfide was obtained from Aldrich Chemical Co. and dimethyldiselenide was obtained from Alfa Chemical Co. 'Tetramethyldistibine [28], tetramethyldibismuthine [1] and dimethylditelluride [29] were prepared by literature methods.

\section{Exchange reactions of the tetramethyldipnictogens with the dimethyldichalcogenides}

Samples for proton NMR spectroscopy were prepared by placing $10 \mu 1$ of each of the tetramethyldipnictogen and the dimethyldichalcogenide and $0.5 \mathrm{ml}$ of benzene- $d_{6}$ in $5 \mathrm{~mm}$ NMR tubes. These samples were also used for the GC/MS analyses. The relative equilibrium concentrations were determined from integration of the proton NMR signals. The equilibrium constants were calculated from eq. 3 . Their values are estimated to be accurate to $10 \%$. It is estimated that concentrations of starting materials $>1 \%$ could be detected. Where conversion to product was essentially complete, a small concentration of one of the starting materials was detected. The minimum equilibrium constants of $10^{3}-10^{4}$ are based upon these concentrations.

Samples from the tellurium NMR spectra of $\mathbf{8 b}, \mathbf{8 c}$ and $\mathbf{8 d}$ were prepared by placing $70 \mu 1$ of dimethylditelluride, $50 \mu \mathrm{l}$ of the tetramethyldipnictogen and $1.5 \mathrm{ml}$ of benzene- $d_{6}$ in $10 \mathrm{~mm}$ NMR tubes. The sample for the tellurium NMR spectrum of 8a was prepared from $10 \mu \mathrm{l}$ dimethylditelluride, $50 \mu \mathrm{l}$ dimethyldiphosphine and $500 \mu 1$ of benzene- $d_{6}$, while the sample for the ${ }^{31} \mathrm{P}$ NMR spectrum was prepared from $50 \mu 1$ of dimethylditelluride, $10 \mu 1$ of dimethyldiphosphine, and $500 \mu 1$ of benzene- $d_{6}$. Samples for Raman spectra were prepared by sealing $10 \mu 1$ each of a tetramethyldipnictogen and a dimethyldichalcogenide in $1 \mathrm{~mm}$ glass capillary tubes.

\section{Acknowledgment}

Support of our work by the A.F.O.S.R. (Grant No. 81-099) is gratefully acknowledged. 


\section{References}

1 A.J. Ashe III and E.G. Ludwig, Jr., Organometallics, 1 (1982) 1403; A.J. Ashe III, E.G. Ludwig, Jr. and J. Oleksyszyn, Organometallies, 2 (1983) 1859. A.J. Ashe III and F. Drone, Organometallics, 3 (1984) 495.

2 A.J. Ashe III, W. Butler and T.R. Diephouse, J. Am. Chem. Soc., 103 (1981) 207; A.J. Ashe III, E.G. Ludwig, Jr. and H. Pommerening, Organometallics, 2 (1983) 1573. A.J. Ashe III, E.G. Ludwig, Jr., J. Oleksyszyn and J.C. Huffman, Organometallics, 3 (1984) 337.

3 A.J. Ashe III, W.M. Butler and T.R. Diephouse, Organometallics, 2 (1983) 1005.

4 A.J. Ashe III and E.G. Ludwig, Jr., J. Organomet. Chem., 303 (1986) 197.

5 P. Dehnert, J. Grobe, W. Hildebrandt and D. le Van, Z. Naturforsch., B, 24 (1979) 1646.

6 J. Grobe and D. Le Van, Z. Naturforsch., B, 34 (1979) 1653.

7 P. Dehnert, J. Grobe and D. le Van, Z. Naturforsch., B, 36 (1981) 48.

8 R.A. Pyles, Ph.D. Dissertation, Texas A and M University, 1982.

9 H.J. Breunig and H. Jawad, J. Organomet. Chem., 277 (1984) 257.

10 W.-W. du Mont, T. Severengiz, H.J. Breunig and D. Müller, Z. Naturforsch., B, 40 (1985) 848.

11 W.-W. du Mont, T. Severengiz and H.J. Breunig, Z. Naturforsch., B, 38 (1983) 1306; M. Wieber and I. Sauer, Z. Naturforsch. B, 39 (1984) 1668.

12 H. Gilman and H.L. Yale, J. Am. Chem. Soc., 73 (1951) 2880. D.N. Kravtsov, B.A. Krasov, S.I. Pombrik and E.I. Fedin, J. Organomet. Chem., 86 (1975) 383; Izv. Akad. Nauk SSSR, Ser. Khim, 23 (1974) 927.

$13 \mathrm{M}$. Wieber, Gmelin Handbook of Inorganic Chemistry, Sb Organoantimony Compounds, Part 2, Springer-Verlag, Berlin (1981) pp. 48-53.

14 L.S. Sagan, R.A. Zingaro and K.J. Irgolic, J. Organomet. Chem., 39 (1972) 301.

15 F. Seel and K.-D. Velleman, Chem. Ber., 105.(1972) 406.

16 H.C. McFarlane and W. McFarlane, J. Chem. Soc., Dalton Trans., (1973) 2416.

17 W.-W. du Mont and H.-J. Kroth, Z. Naturforsch., B, 36 (1981) 332.

18 D.H. O'Brien, N. Dereu, R.A. Grigsby, K.J. Irgolic and F.F. Knapp Jr., Organometallics, 1 (1982) 513; C.H.W. Jones and R.D. Sharma, J. Organomet. Chem., 255 (1983) 61.

19 P. Granger, S. Chapelle, W.R. McWhinnie and A. Al-Rubaie, J. Organomet. Chem., 220 (1981) 149.

20 W. McFarlane and R.J. Wood, J. Chem. Soc., Dalton Trans., (1972) 1397.

21 H.J. Breunig and H. Kischkel, Z. Naturforsch., B, 36 (1981) 1105.

22 G.N. Chremos and R.A. Zingaro, J. Organomet. Chem., 22 (1970) 637 and 647.

23 W. Gordy, J. Chem. Phys., 14 (1946) 305.

24 L. Pauling, Nature of the Chemical Bond, Cornell University Press, Ithaca, N.Y., 3rd ed., 1960.

25 J.R. Durig and J.S. DiYorio, Inorg. Chem., 8 (1969) 2796.

26 J.R. Durig and J.M. Casper, J. Chem. Phys., 55 (1971) 198.

27 H.J. Breunig, V. Breunig-Lyriti and W. Fichtner, Z. Anorg. Allg. Chem., 487 (1982) 111. H. Bürger, R. Eujen, G. Becker, O. Mundt, M. Westerhausen and C. Witthauer, J. Mol. Struct., 98 (1983) 265.

28 H.A. Meinema, H.F. Martens and J.G. Noltes, J. Organomet. Chem., 51 (1973) 223.

29 M.T. Chen and J.W. George, J. Organomet. Chem., 12 (1968) 401; K.J. Wynne and P.S. Pearson, Inorg. Chem., 9 (1970) 106. 